\title{
Las estrategias de Rojas: de cómo una "puta vieja» se convierte en sujeto histórico y literario
}

\author{
Beatriz Calvo Peña \\ University of Miami
}

MuCHOS HAN SIDO quienes tradicionalmente han definido el discurso de La Celestina como misógino, en especial a raíz de las palabras que Pármeno y Sempronio dedican a las mujeres y de la representación de la alcahueta Celestina, dado que en la literatura medieval de corte misógino las alcahuetas jugaban un papel fundamental. En las siguientes páginas trataré de mostrar un punto de vista contrario. ${ }^{1}$ Si bien Francisco de Rojas bebe de la tradición literaria misógina común a las tres culturas que convivieron en la Edad Media peninsular, ${ }^{2}$ en esta obra, lejos de ser degradada la mujer como recipiente de todos los pecados - en especial de la lujuria, como es propio de esta tradición - se ofrece una visión rica y compleja de su cotidianeidad y su intimidad. La Celestina rechaza los estereotipos que relegaban a la mujer a su condición de objeto, otorgándole voz y convirtiéndola en sujeto central de la historia y la literatura. Todo ello con un fin muy claro: dirigir una dura crítica contra la iglesia y el poder político de los cristianos viejos. La hipótesis que trataré de defender en las páginas que siguen es que Rojas se sirve de la voz de las mujeres, y muy en especial de la de Celestina, para juzgar a la sociedad del momento desde su posición de converso. Ello responde a una sutil estrategia apoyada en un elaborado juego de palabras.

1. Entre los que han ofrecido una lectura que rechaza la misoginia de la obra destacan Catherine Swietcliki (1985) y Mary Gossy (1989). La primera afirma que el acercamiento de Rojas a sus personajes femeninos es realista y similar al de los personajes masculinos. (Swietlicki 1985, 2) Gossy desarrolla una interpretación feminista de La Celestina. Coincido enteramente con su opinión de que el texto subvierte los valores patriarcales de la época.

2. Hamilton (1998) expone que los personajes de alcahuetas pertenecen a una literatura didáctica común a las culturas árabe y judía y que de ahí podría haberse visto influido Rojas para la creación de La Celestina. Véase también Muriel Tapia (1991) para la tradición de la misoginia en las culturas orientales y Márquez Villanueva (1987), quien relaciona el tópico de la alcahueta con la tradición semítica. 


\section{«Que toda palabra del hombre sciente esté preñada...»}

La Celestina Viene rodeada de confusión en torno a detalles como su autoría, la primera fecha de su publicación, la intención (didáctica o no) del autor o el género de la obra. Al cabo de cinco siglos, la polémica sigue vigente. Esta confusión no nace de la casualidad. Estaba ya presente en las discusiones sobre la obra mientras el autor vivía, de ahí que el mismo Rojas afirme con respecto a su género: "Yo viendo estas discordias, entre estos estremos partí agora por medio la porfía y llaméla tragicomedia» (81). No parece que su intención fuera aclarar discordias llamando a su obra "tragicomedia», sino más bien perpetuar las existentes. Lo mismo hace en la carta que escribe "a un su amigo", al afirmar que el autor del primer acto "quiso celar e encubrir su nombre, no me culpéys si en el fin baxo que le pongo, no espresare el mío» (70). 'En el fin' de la carta lo que el autor 'pone' es una colección de doce estrofas, 'baxo' las cuales se esconde su propio nombre, su profesión y su origen. Así, Rojas se descubre encubriéndose, o se encubre descubriéndose, y en sus propios versos llama la atención sobre esta paradoja. Lo interesante de estos juegos es que no responden a una mera diversión del artista, sino a una filosofía de vida, a su propia cosmovisión: "Todas las cosas ser criadas a manera de contienda o batalla, dize el gran sabio Eráclito» (69). Con estas palabras comienza el prólogo del libro y he aquí las palabras con que da término: "Por ende si vieres turbada mi mano turvias con claras mezclando razones, dexa las burlas, qu'es paja y grançones sacando muy limpio dentrellas el grano» (344). Contienda, batalla, mezclando turvias con claras razones, paja y grano... Ante una obra que es esencialmente contienda y batalla, ¿cómo extraer el grano?

Para ello hace falta cuestionarse la intención de Rojas al escribir su tragicomedia. El prólogo señala que la obra está "compuesta en reprehensión de los locos enamorados» (82), y que su fin es edificante: "hecho en aviso de los engaños de las alcahuetas y malos y lisonjeros sirvientes» (82). Por mucho que se insista en su fin moral, no encontramos en $\mathrm{La} \mathrm{Ce-}$ lestina un sólo personaje ejemplar que proponga una alternativa de virtud. La codicia, la corrupción, las muertes y el lenguaje obsceno hacen dudar de su intención moral y del supuesto didactismo que autores como Gaspar Barth o Marcel Bataillon han defendido. ${ }^{3}$

3. La tesis del didactismo de la obra de Rojas, desarrollada por Gaspar Barth, Bataillon, Maravall, (1964) (que lo considera un "enxemplo»), ha sido rechazada por muchos, por diferentes razones. Gilman (1978), Américo Castro (1965), María Rosa Lida (1970), entre otros, tienden a coincidir en que la intención de Rojas era más la de hacer crítica social recurriendo a la ironía, a los mensajes judaizantes o al simple humor, y rechazan el objetivo moral en el que Rojas insiste. 
Stephen Gilman señala que el diálogo de Rojas es esencialmente irónico, pues, dado que la minoría conversa a la que pertenecía estaba «sujeta al escarnio y a la sospecha» se vio obligada a desarrollar diferentes estrategias para protegerse, entre ellas «el cultivo a la inteligencia y sus profesiones y la ironía» (Gilman 1978, 40). En un análisis de la voz en La Celestina, Gustavo Illades hace referencia a una estrategia de ocultamiento del discurso marginal, la taquiyya, que consistía en el "acto por el que un musulmán simulaba profesar la religión que el grupo social hostil le quiere imponer» (Illades 1995, 39). La utilización de tal tipo de estrategias entre conversos, la taquiyya y la ironía, hace pensar que bajo el discurso de Rojas regía una estrategia semejante. En mi opinión, la ironía es el recurso articulador básico de la obra, y es esto mismo lo que el autor quiere dar a entender al introducir la metáfora de la palabra preñada en su prólogo: «Y como sea cierto que toda palabra del hombre sciente esté preñada, desta se puede dezir que de muy hinchada y llena quiere rebentar, echando de sí tan crescidos ramos y hojas, que del menor pimpollo se sacaría harto fruto entre personas discretas» (77). He aquí la estrategia de Rojas: su discurso está hinchado de significados ambiguos de los que los lectores debemos extraer el grano.

Gustavo Illades relaciona la palabra preñada de Rojas con el concepto de palabra bivocal desarrollado por Bajtín, que resume del siguiente modo: "Una palabra se vuelve bivocal cuando introducimos en nuestro discurso la palabra ajena. La palabra bivocal llega a ser el cruce de dos conciencias en una, la arena de lucha de dos voces que no pueden fusionarse en una sola» (Illades 1995, 331). Ya Gilman se había referido a esta «bivocalidad» del discurso de La Celestina, aunque con otros términos, al afirmar que Fernando de Rojas, en lugar de hablar directamente de los problemas de los conversos, creó personajes desde los que poder expresar su propio resentimiento, miedo, decepción y cinismo de converso. (Gilman 1978, 380)

Según el análisis que desarrollaré en las páginas que siguen, el discurso de La Celestina se debe entender como «bivocal» por triple partida. En la obra confluyen diferentes códigos que responden a la diferente posición social de cada personaje. Podemos así hablar de un código diferente entre Calisto y Melibea, nobles y entre Celestina y Sempronio. Igualmente hay un código masculino diferente al que utilizan las mujeres para comunicarse entre sí. A ellos se superpone la ironía, el código de Rojas, el que enmarca a todos. Allí donde confluyen dos códigos diferentes se da la «bivocalidad», pues permite la fusión de dos conciencias en una. Por ello, veo una triple dimensión para la «bivocalidad» o las palabras preñadas usadas por Rojas: en ocasiones se fusiona la voz de Rojas con la de sus personajes; en otras se fusionan los códigos de dos personajes; y por último, puede darse la fusión de los códigos de una tradición literaria (didáctica o del amor cortés) con la voz de los personajes. La utilización de palabras 
preñadas se revelará, a raíz de esta definición y del análisis que realizaré a continuación, como la clave retórica de la estrategia de Rojas, una estrategia con gran capacidad de subversión. Gracias a esto se consigue un doble objetivo: desmantelar los valores sociales dominantes y al mismo tiempo gran parte de los tópicos literarios del amor cortés. En la voz de Celestina se concentra la esencia de esta doble subversión.

\section{«Si una piedra topa con otra, luego suena ¡Puta Vieja!...»}

EN LA TRADICIÓN medieval, la representación literaria de la mujer se hacía en virtud de dos aspectos esenciales: si aparecía en compañía de un hombre (del cual era la amada o la esposa) o si aparecía sola. En este último caso, la mujer era incluida dentro de los dos extremos que la definían en cuanto a la actitud sexual que tomase: castidad o lujuria. Así, las páginas de la literatura medieval se llenan, por un lado, de hagiografías de santas y de cánticos a la Virgen, y por otro, de poemas de serranas, pastoras, panaderas y otras mujeres del estamento social más bajo, todas ellas objeto y fuente de lujuria. Las primeras respondían a la imagen de la mujer casta, exenta de sexualidad. Las segundas eran aquéllas que no habían superado su condición natural de ser como la primera mujer, Eva, y como tales eran la encarnación de la tentación y la lujuria. Ambos grupos tienen una cosa en común, y es que en ellos la mujer aparece como un objeto al servicio del hombre: si la mujer lujuriosa es un objeto del deseo del hombre capaz de satisfacer su sed sexual, la mujer casta es un objeto al servicio de las instituciones de la época (principalmente de la Iglesia) y servía además como símbolo o como ejemplo de la capacidad que la mujer lujuriosa tenía de redimirse.

En el trato psicológico de las mujeres, La Celestina rompe con esta tradición al dar cabida a unas mujeres que piensan por sí mismas y que no encajan en los roles que tradicionalmente se les había asignado. Areúsa se convierte en el abanderado de la libertad, pues, aunque prostituta, es más señora de su casa que cualquier noble o burguesa casada: "Por esto me bivo sobre mí, desde que me sé conoscer, que jamás me precié de llamar de otrie sino mía. Mayormente destas señoras que agora se usan» (232). En el otro extremo social, vemos a una doncella de familia rica, Melibea, que toma la iniciativa en el amor en lugar de someterse, que aspira más a amar libremente que al matrimonio y que está dispuesta a rechazar a su familia porque «más vale ser buena amiga que mala casada; déxenme gozar mi mocedad alegre (...) que ni quiero marido, ni quiero padre, ni parientes» (304/305).

Estas mujeres responden a lo que Julio Rodríguez Puértolas llama la mujer nueva del siglo $X V$, resultado de los cambios que la crisis castellana de este siglo. Las palabras recién citadas de Areúsa demuestran algo sorpren- 
dente: que «una mujer está dispuesta a defender su integridad personal, su dignidad, defendiendo su opción entre prostitución y servidumbre, defendiendo su libertad» (Rodríguez Puértolas 1978, 42). De todas las mujeres de la obra, quien encarna la esencia de la transgresión es la alcahueta Celestina, porque sus acciones y sus palabras contribuyen a minar muchos de los valores sociales de la Castilla medieval. Esto es así gracias a las dos características que la definen esencialmente: es vieja y es puta.

Sabemos que Celestina practica un sinfín de oficios, entre otras cosas, cosedora, lavandera, perfumera. También Pármeno dice de ella que es alcahueta y un poquito hechichera (110), pero sobre todas las definiciones que de ella se dan, la expresión que con más fuerza la define es la tantas veces repetida iputa vieja! Así lo señala Pármeno: «desto es nombrada, y por tal título conoscida. Si entre cient mugeres va y alguno dize '¡Puta vieja!', sin ningún empacho luego buelve la cabeça y responde con alegre cara» (109). No hay nadie ni nada en el mundo que no la conozca y no la designe así. Los perros, las aves, las bestias, las ranas de los charcos, los martillos de los herreros, "todo officio de instrumento forma en el ayre su nombre» (109). La exageración llega hasta el límite de que «si una piedra topa con otra, luego suena «!Puta vieja!» (109) La propia Celestina, al borde de su muerte y a modo de despedida de este mundo vuelve a insistir en sus dos rasgos esenciales: "¿Quién soy yo, Sempronio? ¿Quitásteme de la putería? Calla tu lengua; no amengües mis canas, que soy una vieja qual Dios me hizo» (273).

Como puta, el oficio de Celestina es servir al placer sexual de los hombres. Sin embargo, como vieja, hace tiempo que dejó de ser objeto de deseo para éstos. De este modo, lo que parece un insulto resulta ser una identificación de Celestina con su falta de sumisión al poder masculino. Celestina es independiente, no está cosificada por el deseo de ningún otro, no es objeto de nadie, todos dependen de ella. Es el sujeto libre por excelencia. En esta libertad absoluta que Rojas concede a la vieja alcahueta reside la transformación de la 'puta vieja' en sujeto histórico.

A lo largo de la obra se hacen múltiples referencias a su vejez y se insiste en ponerle número a su edad. Pármeno dice: «Si yo creyera a Celestina con sus seys dozenas de años a cuestas» (137), y más tarde vuelve a referirse a su edad: "Y esta puta vieja querría en un día por tres passos desechar todo el pelo malo quanto en cinquenta años no ha podido medrar» (178). Cuando va a ser asesinada Celestina suplica que no hagan daño a «una vieja de sesenta años» (273). Claro que la alcahueta se caracterizaba como una mujer vieja en la tradición literaria, pero dado que no debemos considerar casual casi ningún elemento de la obra de Rojas, es posible que la insistencia en su vejez no pretendiera simplemente seguir la tradición, sino dejar bien claro que Celestina ha vivido una cantidad de años concreta. Dado que generalmente se acepta la idea de que Rojas está reflejando con detalle realista la misma sociedad en que vivió y que 
leyó su obra por primera vez, ${ }^{4}$ es decir la España del cambio de siglo, la insistencia en su edad no es intranscendente. Supone que esta mujer ha vivido los grandes cambios de la Península en la segunda mitad del siglo XV: la crisis castellana, la formación del reino de España, la reconquista del reino de Granada, la expulsión de judíos y moriscos, los avances en materia de ciencia y cultura, la apertura de nuevas rutas a las Indias que abrían igualmente un futuro brillante para el país. La tierra en crisis que Celestina conoció en su juventud se había convertido ahora en un país próspero con un futuro prometedor. ${ }^{5}$ Insistir tanto sobre los años de Celestina, ¿no sería una manera de dirigir la atención del lector hacia el testimonio histórico entretejido en la voz y las memorias de la vieja Celestina? El hecho de que en La Celestina no aparezca ninguna referencia histórica directa que sitúe la acción en el tiempo y en el espacio, da a la memoria de una vieja un valor incalculable, pues es su colección de recuerdos lo que aporta dimensión histórica a la obra.

En la memoria de Celestina estaban presentes, entre otros, la emigración masiva masculina del campo a la ciudad y la miseria de los estamentos más bajos, especialmente de las mujeres. Una gran cantidad de hombres solos se concentraron en las ciudades, meca para el buscador de oportunidades, al tiempo que las mujeres se vieron obligadas a trabajar en lo que pudieran o supieran hacer para huir de la pobreza: la crisis y la prostitución son compañeras de batalla. ${ }^{6}$ Los Reyes Católicos llevaron a cabo toda una serie de iniciativas para conseguir una mayor estabilidad social en la Península. La prostitución, ese sector tan necesario como indeseable, no encajaba en un proyecto de construcción cultural y social católico y desde un principio hubo un gran interés por reglamentarla. ${ }^{7}$ El recurso a la memoria de Celestina, y con ello al mundo de la prostitución, es una de las armas más poderosas de Rojas para atacar a la Iglesia y al poder real.

4. P. E. Russell (1989) propone que Celestina pudo tratarse de un personaje real, que vivió en Salamanca en los tiempos de estudiante de Rojas.

5. Elena Gascón Vera (1999) insiste en el triángulo que forman los Reyes Católicos, Colón y Fernando de Rojas como representantes de esa España en cambio y opina que sus acciones muestran «un deseo de afianzamientoo personal que estabilice la inquietud social que sienten en unos años de profunda crisis y cambio» (301). Esta idea afianza la necesidad que tuvo Rojas de utilizar a una vieja como su portavoz y testigo de los cambios.

6. Así lo afirma Márquez Villanueva (1987), para quien en el exceso de población masculina en movimiento se dio un impulso para la prostitución y la alcahuetería (330).

7. En 1476 los Reyes Católicos establecieron el derecho de perdices, que obligaba a pagar una cuantía similar anualmente a todas las prostitutas del reino (Lacarra 1993, 39). A partir de la década de 1490, los Reyes hicieron mayores esfuerzos por controlar la prostitución en las tierras de Castilla (en Aragón se había comenzado antes), que se tradujo en una reglamentación de los detalles de la vida de las prostitutas y en la creación de mancebías y ramerías — dadas en explotación a un hombre de confianza del rey- en casi todas las ciudades de Castilla a finales del siglo Xv. Para más información sobre este aspecto véase Lacarra (1993), María Asenjo (1984), Segura Graíño (1984) y Galán Sánchez (1984). 
El autor es consciente de ello y lo explota. ${ }^{8}$ Esta era una excusa ideal para lanzar su crítica contra la hipocresía social que subyacía a la reglamentación de la prostitución. (Segura Graíño 1984, 147) Por un lado, la razón que se daba para reglamentar la prostitución era la necesidad de evitar escándalos públicos (Galán Sánchez 1984, 162) y controlar la sanidad de las prostitutas. Sin embargo, el interés monetario que iba aparejado a la reglamentación dio lugar a muchos desórdenes en lo referente a la administración de las mancebías, y a un empeoramiento de la situación de las prostitutas. Además no logró evitar la prostitución clandestina, dado que muchos hombres acudían a mujeres enamoradas para evitar deshonrarse al acudir a la mancebía pública. (Lacarra 1993, 45) No sólo la reglamentación se había llevado con hipocresía, la prostitución clandestina era igualmente producto de esta hipocresía, como recuerda la propia Celestina al hablar de sus visitas a la iglesia, donde «se concertavan sus venidas a mi casa, allí las ydas a la suya. Allí se me offrescían dineros, allí promessas, allí otras dádivas, besando el cabo de mi manto» (235). El interés por los detalles con que se refleja la vida del prostíbulo y el recurso a la memoria de Celestina, especialmente en su monólogo del acto IX, es una poderosa estrategia de Rojas para criticar a la Iglesia y a los cristianos viejos.

Las diferentes actitudes ante la vida de Celestina y de Areúsa reflejan estos cambios sociales. "Areúsa, enamorada, medio ramera» (293) es una prostituta clandestina, que parece ejercer la prostitución por su placer y su amor a la libertad, hija de un período de prosperidad general. A través de los detalles de la vida de Celestina (se ha tenido que trasladar de un barrio céntrico a una casa en las afueras de la ciudad, ha visto reducido el número de mochachas que vivían bajo su techo, ha perdido la honra que todos le guardaban en su juventud) se pone de manifiesto el paso de una crisis profunda a un momento de estabilidad económica. ${ }^{9}$ La miseria y decadencia castellana fueron las que le habían proporcionado en un principio tanta honra y una casa tan bien surtida: «Cavalleros, viejos y moços, abades de todas dignidades, desde obispos hasta sacristanes. En entrando por la yglesia vía derrocar bonetes en mi honor como si yo fuera una duquesa (...) Qué hombre avía, que estando diziendo missa en viéndome entrar se turbavan, que no hazían ni dezían cosa a derechas. Unos me llamavan señora, otros tía, otros enamorada, otros vieja honrrada» (235).

Fijémonos en esta última palabra: honrada. Una de las mayores ironías que despliega el autor en relación con el mundo de las prostitutas está relacionada con el significado de la palabra honra. Es uno de los casos de

8. En la segunda escritura de la obra de Rojas, la Tragicomedia de Calisto y Melibea, gran parte de las interpolaciones se dedican a aumentar el dicurso celestinesco (según la edición de Severin.) Además, de los cinco actos interpolados, tres se dedican a las 'mochachas' y los rufianes que conocen. El interés de Rojas se decantó por este mundo marginal probablemente al notar la capacidad subversiva que tenía.

9. Para un análisis detallado de la situación de Celestina y de Areúsa: Lacarra 1993, 46-48. 
palabras preñadas a las que me referí en un principio. En este tiempo, la honra se entendía bien como «homenaje personal que se rendía a Dios, al rey o a quien aventajaba en jerarquía» bien como "categoría social que se adquiría por concesión divina o regia por el propio esfuerzo o la provia virtud ${ }^{10}$ (Sánchez-Albornoz 1962, 626). Llama la atención que Pleberio no haga referencia al honor o a la honra en el llanto por su hija. La palabra honra en el llanto de Pleberio aparece en plural, "honrras», de manera que carece de valor espiritual, y adquiere uno económico: «Para quién edifiqué torres; para quién adquirí honrras; para quién planté árboles, para quién fabriqué navíos?» (337) En cambio, Celestina usa la palabra honra a menudo para referirse a su paso por el mundo: «En esta ciudad nascida, en ella criada, manteniendo honrra, como todo el mundo sabe, ¿conocida, pues, no soy? Quien no supiere mi nombre y mi casa, tenle por estrangero» (142) y a menudo es llamada honrada por todos los personajes. En el caso de Celestina, la honra es algo que le viene dado desde afuera, por la sociedad en que nació y vivió, es un valor humano. En el caso de Pleberio se trata de algo adquirido, material, un bien más que se compra. Se atribuye la honra a algo propio de una prostituta, al tiempo que se le niega al rico burgués.

La riqueza subversiva de esta palabra va todavía más allá. Si pensamos en que el oficio de Celestina es hacer y deshacer hímenes, es decir 'remedar', la honra adquiere un nuevo significado en estas palabras que Melibea dirige a Celestina cuando es instada a ceder ante Calisto: "haz lo que supieres, que no podrá ser tu remedio tan áspero que yguale con mi pena y tormento. Agora toque en mi honrra, agora dañe mi fama, agora lastime mi cuerpo, aunque sea romper mis carnes para sacar mi colorido coraçón, te doy mi fe ser segura, y si siento alivio, bien galardonada» (242). El uso de los verbos en este fragmento: tocar, dañar, lastimar, romper las carnes, sentir aliento, adquiere una innegable connotación sexual, que invitan a entender la honra con un significado diferente al recogido por SánchezAlbornoz. A la luz de este código femenino, la honra es equivalente al himen de la doncella Melibea.

El juego creado alrededor de la honra se enriquece cuando Celestina introduce un término casi sinónimo: la buena fama. La ironía de Rojas asocia este término con la voz de Celestina cuando habla de sus prácticas de brujería con Claudina: "Siete dientes quitó a un ahorcado con unas tenazicas de pelar cejas, mientra yo le descalcé los çapatos. Pues entrar en un cerco, mejor que yo, y con más esfuerço, aunque yo tenía harta buena

10. Sánchez-Albornoz $(1962,614-667)$ recoge todo el sentido que esta palabra tenía en la Edad Media. Asociada en primer lugar al honor caballeresco, llegó a significar el honor y el respeto ganado que no dependía tan sólo del individuo, sino también de su familia, y en particular del honor de las mujeres de la familia. Desarrolla también la idea de la fama, el orgullo y la dignidad. 
fama, más que agora» (196-97). Si la honra es algo propio de las mujeres y está en dos atributos por los que se las consideraba inferiores al hombre - su oficio y su cuerpo,- - la buena fama se consigue en La Celestina a través de la profanación de tumbas y de la práctica de la magia negra.

La subversión es evidente. Además, la adjudicación de estos valores a una 'puta vieja' adquiere una dimensión que toca directamente a Rojas en su calidad de converso, pues la honra era asociada por los cristianos viejos con la limpieza de sangre, tal como afirma Egido: «A aquellas alturas (después de 1492) ya se había estructurado un discurso mental, religioso, social, tan poderoso como sutil, que cifraba el supremo valor social en la honra, pero, dentro de su complejidad, en una honra reducida, en la más genuina de sus expresiones, a la ausencia de cualquier sospecha de contaminación castiza, conversa» (Egido 1990, 169). Rojas se sirve de esta palabra en boca de Celestina y Melibea para parodiar uno de los bastiones de poder de los cristianos viejos, el más poderoso que habían desarrollado contra los conversos. Si la honra era para éstos la limpieza de sangre, en La Celestina adquiere un doble significado: el respeto ganado por el ejercicio de la prostitución, la alcahuetería o la brujería y el himen de una doncella.

\section{"¡Ay, dolor! Peresció mi remedio»...}

LAS MAYORES ALUSIONES a la sociedad del momento se hacen a través de los actos, los juicios y la memoria de Celestina. Celestina tiene el privilegio de ser el único personaje capaz de acceder a todos los espacios sociales que estaban reservados según grupos sociales: desde el burdel, pasando por las casas de los nobles, hasta la iglesia y los monasterios. Como vieja, es testigo único de la historia, como prostituta y alcahueta, es conocedora de las intimidades humanas, por lo que su rol social hace de su voz un testimonio y puede ser un arma de gran valor. Estas y otras razones me llevan a proponer que Celestina es la auténtica protagonista de la obra de Rojas, y que el título de Comedia y luego Tragicomedia de Calisto y Melibea que Rojas dio a su obra, situando a los dos amantes como protagonistas, responde a una de sus estrategias: cumple con los cánones de la literatura medieval (la alcahueta es un personaje secundario que enlaza a los amantes protagonistas) y al mismo tiempo los rompe, pues Celestina se acaba destacando como la verdadera protagonista. Mi afirmación necesita una amplia explicación, y es lo que me propongo hacer en estas últimas páginas.

La primera paradoja con la que nos enfrentamos al analizar el personaje de Celestina consiste en que es un personaje marginal de su sociedad y al mismo tiempo ocupa una posición nuclear, dado que todos los estamentos sociales entran en contacto a través de sus acciones. Es Celestina 
quien enlaza a todos, pues cada uno depende de ella para conseguir algo de otro (los sirvientes para conseguir dinero de su amo, Calisto y Melibea para amarse.) Esta paradoja forma parte una vez más de la contienda, la ambigüedad con que Rojas quiso dotar a su obra. De la misma manera que la crítica y la subversión aparecen disfrazadas de discurso moralizante, el protagonismo de Celestina aparece disimulado de personaje marginal. El título de la obra y el hecho de que comience con el encuentro y termine con la muerte de los dos amantes está encubriendo (tal como ya hiciera al esconder su nombre en los versos acrósticos) la intención última de Rojas. La da a conocer como una historia ejemplar (en el sentido medieval), por lo que Celestina no podía salir indemne de sus actos destructivos y la muerte la esperaba implacable. Sin embargo, dado que la obra está articulada a través de la ironía, cabe entender la muerte de la alcahueta desde una nueva perspectiva, que ahora explicaré.

Hay dos asuntos a resolver para afirmar el protagonismo de Celestina: el de su muerte prematura y el de los códigos lingüísticos usados por los personajes. Alguien preguntará cómo se puede afirmar el protagonismo de Celestina si la obra sigue adelante aún después de su muerte, sin su presencia. Encuentro en la obra dos respuestas a esta cuestión: la primera es de índole filosófica, y tiene que ver con el concepto del tiempo y el carpe diem que acompaña al inicio del Renacimiento; la otra tiene que ver específicamente con el desarrollo de la acción. En ambas veremos nuevos aspectos de la ironía transgresora de Rojas.

La conciencia del paso del tiempo fue ganando importancia a lo largo del siglo XV, tanto como resultado de un período de grandes cambios en que el concepto de tiempo se revalorizó, como a través del desarrollo de la vida urbana, con la aceleración y la dependencia del tiempo que ello supuso. ${ }^{11}$ El Renacimiento significó además un movimiento de una visión del mundo teocéntrica a una visión enfocada en el ser humano como individuo. Ganó importancia la preocupación por los asuntos mundanos, al tiempo que, según afirma Hartunian, "a growing self-consciousness occurred (...) Self-consciousness triggered emphasis on the senses and on sensuality" (Hartunian 1992, 16). Desde esta perspectiva se entiende el acento que Rojas pone en los deleytes y donayres, su énfasis en el gozo sexual y en el disfrute de la comida y la bebida.

El ideal de vida celestinesco se basa en el carpe diem, filosofía en la que se reúnen la conciencia sobre el paso del tiempo, la transitoria e incierta naturaleza de la vida, la juventud y la belleza (Hartunian 1992, 6). Celestina es máximo exponente, profeta, portavoz del carpe diem. Así lo resumen sus consejos a Pármeno: "Goza tu mocedad, el buen día, la buena noche,

11. Maravall $(1964,64)$ señala la importancia que tiene el reloj como instrumento del que se sirven para medir y ordenar su tiempo todos los personajes. Para el autor esto se debe a la caracterización urbana del mundo de La Celestina. 
el buen comer y bever. Quando pudieres averlo, no lo dexes; piérdase lo que se perdiere. No llores tú la hazienda que tu amo heredó, que esto te llevarás deste mundo, pues no le tenemos más de por nuestra vida» (195), y al resto de los jóvenes: "Gozad vuestras frescas mocedades, que quien tiempo tiene y mejor le espera, tiempo viene que se arrepiente, como yo fago agora por algunas horas que dexé perder quando moça, quando me preciava, quando me querían, que ya, mal pecado, caducado he; nadie no me quiere» (231). En el hecho de que Celestina sea la portavoz de esta filosofía de vida Hartunian ve un aspecto innovador de la obra, pues en la poesía del carpe diem la voz era siempre de un hombre, la mujer no tenía autoridad (Hartunian 1992, 80).

A la filosofía del carpe diem se suma la aceptación de la irremediabilidad de la muerte, de la que los personajes son conscientes en todo momento, pues como dice Celestina, «ninguno es tan viejo que no pueda bivir un año, ni tan moço que hoy no pudiesse morir» (157). En una obra que refleja como ninguna los conflictos de la sociedad urbana justo anterior al Renacimiento no podía faltar este papel central de la preocupación por el tiempo y la muerte. Las muertes se ven así más que justificadas, y la de Celestina en especial, pues el carpe diem conlleva el desdén hacia la vejez y la exaltación de la juventud. No debe extrañarnos que la obra no termine con la muerte de Celestina. Precisamente el hecho de que siga adelante sin ella refuerza la importancia de su filosofía del carpe diem. Tras su muerte, es Areúsa quien toma el relevo como profeta del carpe diem. El diálogo entre Areúsa y Elicia a la muerte de Celestina es el momento más optimista de la obra, que pone de manifiesto lo que Deyermond llamó «la capacidad regenerativa de ave fénix» de la sociedad femenina creada por Rojas. (Deyermond 1993, 17)

El otro aspecto que apoya el protagonismo de Celestina viene dado por su oficio y su rol social, y por lo tanto por el código que utiliza. Mi hipótesis en este punto es que la ironía de Rojas se despliega a través del código de Celestina, que es el que dota de sentido al entramado ideológico y a los valores contenidos en la obra. A través de la comprensión de las palabras preñadas usadas por Celestina se desentraña el sentido último de la transgresión social que busca la obra.

Aunque sea capaz de desempeñar mil oficios, la propia Celestina se identifica desde el principio con el cirujano: "como los cirurjanos de los descalabrados, y como aquéllos dañan en los principios las llagas, y encarescen el prometimiento de la salud, ansí entiendo yo hazer a Calisto» ${ }^{12}$

12. La representación de Celestina como curandera ha sido asociada también con un fin misógino. Según señala Jean Dangler (1997), el objetivo que perseguía Rojas era el de desprestigiar la labor de estas mujeres porque a finales del siglo XV se quiere institucionalizar la profesión médica y limitar su ejercicio a los hombres con una preparación universitaria en medicina. 
(107). En otra ocasión, habla de sí misma como de una araña que cose su tela para que caigan en ella las jóvenes: «Pocas virgines, a Dios gracias, has tú visto en esta ciudad que hayan abierto tienda a vender, de quien yo no haya sido corredora de su primer hilado. En nasciendo la mochacha, la hago scrivir en mi registro, y esto para que yo sepa quántas se me salen de la red» (141). Su oficio de cosedora no es nada excepcional si se piensa que en toda la Edad Media esta ocupación era propia de todas las mujeres, ricas y pobres, trabajadoras y ociosas. Sin embargo, en el caso de Celestina, esta ocupación tiene ciertos matices.

Cuando Pármeno enumera todos los oficios de la vieja alcahueta dice ser el principal el de labrandera, que servía para cubrir los otros, pues «muchas de estas sirvientes entravan en su casa a labrarse» (110), y añade: "y remediava por caridad muchas huérfanas y erradas que se encomendavan a ella» (112). En el juego de palabras remedio/ remediar subyace la clave de las muertes de la tragicomedia. Antes de morir, Melibea se lamenta de la muerte de su amado, gritando a su padre: "Peresció mi remedio» (330). He aquí una de esas palabras preñadas que se debe entender desde diferentes códigos. Tomado en su contexto inmediato, la palabra remedio y el uso que hace de ella justo después de la muerte de Calisto, conecta esta palabra con la tradición del amor cortés, según la cual Calisto sería el remedio de la vida de Melibea, 'el amado'. Sin embargo, a lo largo de la obra aparece con otro significado y confrontada con los códigos de Celestina adquiere un nuevo significado y da otro sentido a la muerte de Melibea. Una noche que Celestina llega tarde a casa, le dice Elicia: «Que as seýdo hoy buscada del padre de la desposada que levaste el día de pascua al racionero, que la quiere casar daquí a tres días y es mentes que la remedies, pues que lo prometiste, para que no sienta su marido la falta de virginidad» (209). Relacionando ahora remedio con el oficio de Celestina, se entiende que Melibea se suicida porque ha muerto Celestina, la única capaz de darle remedio, en otras palabras, de remedar su virgo y devolverle la honra social. El remedio de Melibea no es ya Calisto, sino Celestina en su calidad de cosedora de virgos. La necesidad que de ella hay hasta el último momento viene además corroborada por las palabras del mismo Pleberio: «Si tú me cuentas tu mal, luego será remediado, que ni faltarán medicinas ni médicos ni sirvientes para buscar tu salud, agora consista en yervas o en piedras o palabras o esté secreta en cuerpos de animales» (330). En esta ocasión, la palabra remedio alude a la hechicería, de quien era maestra la difunta Celestina.

De este modo, después de muerta, Celestina adquiere protagonismo de nuevo y en un momento culminante. Ella es la cosedora de la sociedad, la que liga a todos los personajes, la remedadora de sus problemas y sus deseos. La muerte de Celestina significará la desintegración de lo que ha creado, se descose la red social que ella había ido cosiendo y así van muriendo uno por uno los personajes. Por ello es la primera en morir. Faltando 
aquélla que ha cosido a todos, pronto empezarán a morir todos al caer en la solubilidad de su individualismo.

Celestina ocupa además un lugar central en la ficción de la obra y como portavoz del pensamiento de su autor. De entre todos los personajes, ella era la única que podía ostentar una cosmovisión similar a la de su creador. Rojas encubrió su propia crítica social bajo las palabras de una alcahueta, con las que fusiona y confunde su voz y su visión de la sociedad. Esta fusión habría sido facilitada por dos aspectos: En primer lugar, el conocimiento que Rojas, como letrado y estudiante de Salamanca debía tener del mundo prostibulario. ${ }^{13}$ Márquez Villanueva ha llamado la atención sobre este factor, pues dice que Salamanca era reconocida como un centro de prostitución en Castilla y que, tal como la comedia humanística fue escrita por intelectuales universitarios, La Celestina y sus imitaciones están también ligadas a este ambiente. ${ }^{14}$ En segundo lugar, el hecho de que tanto conversos como prostitutas fueron víctimas de la represión inquisitorial y de un sistema legal diseñado para controlarlos, leyes nacidas de la hipocresía social y de la necesidad de encontrar un recipiente para los males de la sociedad. ${ }^{15}$ Con respecto a las leyes que se ocupaban de las mujeres, nos dice Segura Graíño que «no hay ninguna disposición referente a las mujeres (...) están totalmente al margen de la vida política» (146). Una exclusión similar a la de las mujeres es la que se llevó a cabo con los conversos. Los Reyes Católicos en un principio no practicaron una política anticonversa, pero una vez que los judíos fueron expulsados, y con la fuerza que había adquirido la Inquisición, los esfuerzos por aniquilar a los judíos se dirigieron hacia los cristianos nuevos, pues eran acusados de judaizantes. ${ }^{16}$

Aunque desde diferentes ángulos, Rojas y su personaje Celestina ocupaban un lugar marginal y al mismo tiempo central en la sociedad que $\mathrm{La}$ Celestina pretendía satirizar. El uno desde la realidad, la otra en la ficción,

13. Rojas era letrado y abogado, y como tal un conocedor de las leyes, de manera que es de suponer que conociera las regulaciones que se estaban llevando a cabo en la ciudad de Salamanca en los tiempos en que vivió allí como estudiante, tal como señaló Lacarra (1993).

14. Márquez Villanueva (1987) sugiere que este género está intrínsecamente ligado al mundo académico porque "an attitude of proud, independent criticism of social realities has looked to the loose sexual mores around the university as its most immediate target [...] The Celestinas constitute a genre which is by definition «academic» and even conspicuously grafted to Salamanca itself» (338-342).

15. La persecución de los judíos y la reglamentación de la prostitución comenzaron en épocas similares, hacia finales del siglo XIV. Ambos acontecimientos fueron provocados por la Iglesia Católica, que al parecer, en el período de crisis de finales del XIV tuvo que buscar un cabeza de turco recipiente de todos los males de la sociedad. Las prostitutas, los judíos, y una vez expulsados éstos, los conversos, fueron los sectores sociales que más duramente se reprimieron.

16. Para la historia de los judeoconversos en este período, véase Américo Castro (1965), Stephen Gilman (1978) y Antonio Domínguez Ortiz (1955) y los artículos de Teófanes Egido (1990) y Martínez Millán (1990). 
ambos fueron seres marginales y objetivos a controlar por la Inquisición: Celestina en su calidad de mujer sola, vieja, y medio hechicera, tachada de bruja o alcahueta, y Rojas en su condición de converso, tachado de judaizante. Al mismo tiempo, sus oficios les otorgaban una posición nuclear, pues tanto las alcahuetas, hechiceras y terceras, como los conversos, tradicionalmente médicos o abogados, eran para la sociedad mediadores.

Comencé estas páginas haciendo mención a la misoginia y a las estrategias de Rojas y acabaré del mismo modo. Las mujeres de La Celestina escapan al control del poder a través de la prostitución clandestina, o bien usando sus oficios para obtener otros beneficios, entre ellos, decidir sobre su vida sexual. Todos sus actos responden a una estrategia femenina que subvierte el poder patriarcal, pero que siempre actúa bajo sus cánones. Esta estrategia es similar a la que Rojas como converso utiliza para subvertir el orden social: su escritura se enmarca en los cánones y códigos literarios tradicionales, sin embargo introduce elementos que rompen con esa tradición; su discurso es acorde con la moral de su época, sin embargo los valores morales dominantes se ven subvertidos a través de un inteligente uso de los códigos. La sociedad femenina dibujada por Rojas mostraba una manera de vivir en libertad bajo el control opresor del imperio naciente español, lo cual era posible gracias a la utilización de una estrategia adecuada. A través de la actuación de las mujeres de $L a$ Celestina y gracias a lo que Deyermond llamó su capacidad regenerativa de ave fénix, Rojas ofrece una vía de escape al mundo falso del que se lamenta Pleberio, el de los cristianos viejos, abre una posibilidad para la expresión de su resentimiento de converso y una vía de escape a la opresión a que estaban sometidos los suyos. Al ceder estratégicamente su voz a una 'puta vieja' Rojas hace de una mujer marginal un sujeto central en la historia y la literatura española.

\section{Bibliografía}

ASENJO GONZÁLEZ, María. «Las mujeres en el medio urbano a fines de la Edad Media: El caso de Segovia", en Las mujeres en las ciudades medievales: actas de las terceras jornadas (Madrid: Jornadas de Investigación Interdisciplinaria de la Universidad Autónoma de Madrid, 1984), pp. 109-124.

CASTRO, Américo. La Celestina como contienda literaria (castas y casticismos). Madrid: Ediciones de la Revista de Occidente, 1965.

DANGLER, Jean. Mediating Fictions: Women Healers and the Go-Between in Medieval and Early Modern Iberia. Atlanta: Emory University, 1997

DEYERMOND, Alan. "Female Societies in Celestina». Fernando de Rojas and Celestina: Approaching the Fifth Centenary. Eds. Ivy A. Corfis and 
Joseph T. Snow (Madison, WI: The Hispanic Seminary of Medieval Studies, 1993), pp. 1-31.

DOMÍNGUEZ ORTIZ, Antonio. La clase social de los conversos en Castilla en la Edad Moderna. Vol. III. Madrid: Consejo Superior de Investigaciones Científicas, 1985.

- «La mujer en el tránsito de la Edad Media a la Moderna», en Las mujeres en las ciudades medievales: actas de las terceras jornadas (Madrid: Jornadas de Investigación Interdisciplinaria de la Universidad Autónoma de Madrid,1984), pp. 171-179.

EGIDO, Teófanes. "El problema histórico de los judeos-conversos españoles» en Las tres culturas en la Corona de Castilla y los Sefardíes (Valladolid: Junta de Castilla y León. Consejería de Cultura y Bienestar Social, 1990).

GALÁN SÁNCHEZ y LÓPEZ BELTRÁN. «El 'status' teórico de las prostitutas del reino de Granada en la primera mitad del siglo XVI (las ordenanzas de 1538.)» en Las mujeres en las ciudades medievales: actas de las terceras jornadas (Madrid: Jornadas de Investigación Interdisciplinaria de la Universidad Autónoma de Madrid, 1984), pp. 161-169.

GASCÓN VERA, Elena. "La Celestina, los Reyes Católicos y el descubrimiento", en Literatura hispánica, Reyes Católicos y Descubrimiento (Barcelona: Actas del congreso internacional sobre literatura hispánica en la época de los Reyes Católicos y el Descubrimiento, 1999), pp. 297-303.

GILMAN, Stephen. La España de Fernando de Rojas. Madrid: Ediciones Taurus, 1978.

GOSSY, Mary S. The Untold Story (Women and Theory in Golden Age Texts). Ann Arbor: University of Michigan Press, 1989.

HAMILTON, Michelle M. «Celestina and the Daughters of Lilith» Bulletin of Hispanic Studies. LXXV (1998): 153-173.

HARTUNIAN, Diane. 'La Celestina': A Feminist Reading of the Carpe Diem. Scripta Humanistica 75. Potomac, Maryland, 1992.

ILLADES, Gustavo. "La voz como diálogo o contienda en La Celestina» Palabra e Imagen en la Edad Media: actas de las IV Jornadas Medievales. Eds. Aurelio González, Walde Moheno y Lillian Von Der (México: Universidad Autónoma de México, 1995), pp. 327-337.

LACARRA, María Eugenia. «La evolución de la prostitución en la Castilla del siglo XV y la mancebía de Salamanca en tiempos de Fernando de Rojas", en Fernando de Rojas and Celestina: Approaching the Fifth Centenary. Eds. Ivy A. Corfis and Joseph T. Snow (Madison WI: The Hispanic Seminary of Medieval Studies, 1993), pp. 33-78.

- «El fenómeno de la prostitución y sus conexiones con La Celestina» en Historias y ficciones (Valencia: Universitat de Valencia, 1990), pp. 267-287.

LIDA DE MALKIEL, Rosa. La originalidad artística de La Celestina. Buenos Aires: Editorial Universitaria de Buenos Aires, 1970. 
MARAVALL, José Antonio. El mundo social de "La Celestina». Madrid: Gredos, 1964.

MÁRQUEZ VILLANUEVA, Francisco. "La Celestina as hispano-semitic anthropology». Revue de Littérature Comparée 61 (1987): 325-53.

MURIEL TAPIA, María Cruz. Antifeminismo y subestimación de la mujer en la literatura medieval castellana. Cáceres: Editorial Guadiloba, 1991.

RODRÍGUEZ PUÉRTOLAS, Julio. "Amor, sexualidad, y libertad: la mujer en la literatura castellana del siglo XV», en Historia social de la literatura española (en lengua castellana.) Eds. Carlos Blanco Aguinaga, Julio Rodríguez Puértolas, Iris Zavala (Madrid: Castalia, 1978).

- "La mujer nueva en la literatura castellana del siglo XV», en Literatura hispánica, Reyes Católicos y descubrimiento (Barcelona: Actas del congreso internacional sobre literatura hispánica en la época de los Reyes Católicos y el descubrimiento, 1999), pp. 38-56.

ROJAS, Fernando de. La Celestina. Edición de Dorothy S. Severin. Madrid: Cátedra, 1998.

RUSSELL, P.E. "Why did Celestina Move House?», en The Age of the Catholic Monarchs 1474 - 1516 (Liverpool: Literary Studies in Memory of Keith Winnom, 1989): pp. 155-161.

SÁNCHEZ-ALBORNOZ, Claudio. España. Un enigma histórico. Vol. 1. Buenos Aires: Editorial Sudamericana, 1962.

SEGURA GRAÍÑO, Cristina. "Las mujeres en la Baja Edad Media (Ordenamientos y ordenanzas municipales)", en Las mujeres en las ciudades medievales: actas de las terceras jornadas (Madrid: Jornadas de Investigación Interdisciplinaria de la Universidad Autónoma de Madrid, 1984), pp. 143-152.

SWIETLICKI, Catherine. "Rojas' view of women: a reanalysis of La Celestina». Hispanófila 85 (1985): 1-13.






\section{Calvo Peña, Beatriz, "Las estrategias de Rojas: de cómo una 'puta vieja' se convierte en sujeto histórico y literario", Celestinesca 27 (2003), pp. 43-60.}

\section{RESUMEN}

EN EL PRESENTE ensayo se reflexiona sobre la voz de Francisco de Rojas a través del personaje de Celestina. La tesis es que Rojas utilizó la tradición misógina medieval, de tipo didáctico, como una excusa para su objetivo único de lanzar una dura crítica contra la sociedad de cristianos viejos. Para ello, utiliza técnicas propias de los conversos, como la ironía, y sus propias estrategias: las palabras preñadas (lo que Bajtín llamó "palabras bivocales», consistentes en la fusión de dos conciencias en una voz.) El ensayo considera honra y remedio como las palabras preñadas principales. A partir de ellas se puede desentrañar el objetivo subversivo del autor. Al analizar esta estrategia, se verá que la voz de Celestina se ha de identificar con la de su autor y que ésta se convierte en protagonista absoluto de la obra y en el sujeto histórico ideal para la efectiva y disimulada sátira social diseñada por Rojas.

PALABRAS CLAVE: Celestina, "puta vieja», personaje histórico, misoginia.

\section{ABSTRACT}

THIS ESSAY IS a reflection on how Francisco de Rojas expresses himself through Celestina's voice. The thesis is that he used the Medieval misogynistic tradition, which was didactic, as an excuse for his only objective: to create a harsh critic against the Old Christian society. For this purpose, he uses typical converso techniques, such as irony, and his own strategy: the use of palabras preñadas (those called «bivocal words» by Bajtin, which consist of the fusion of two consciences in one voice.) This essay considers honra and remedio as the main palabras preñadas. From their analysis it is possible to unravel the author's subversive objective. Rojas voice is identified with Celestina's voice and the old whore will be viewed as the absolute protagonist and as the ideal

KEY WORDS: Celestina, «old whore», historical and literary subject, misogyn.

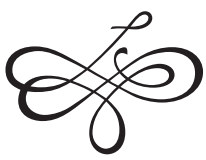




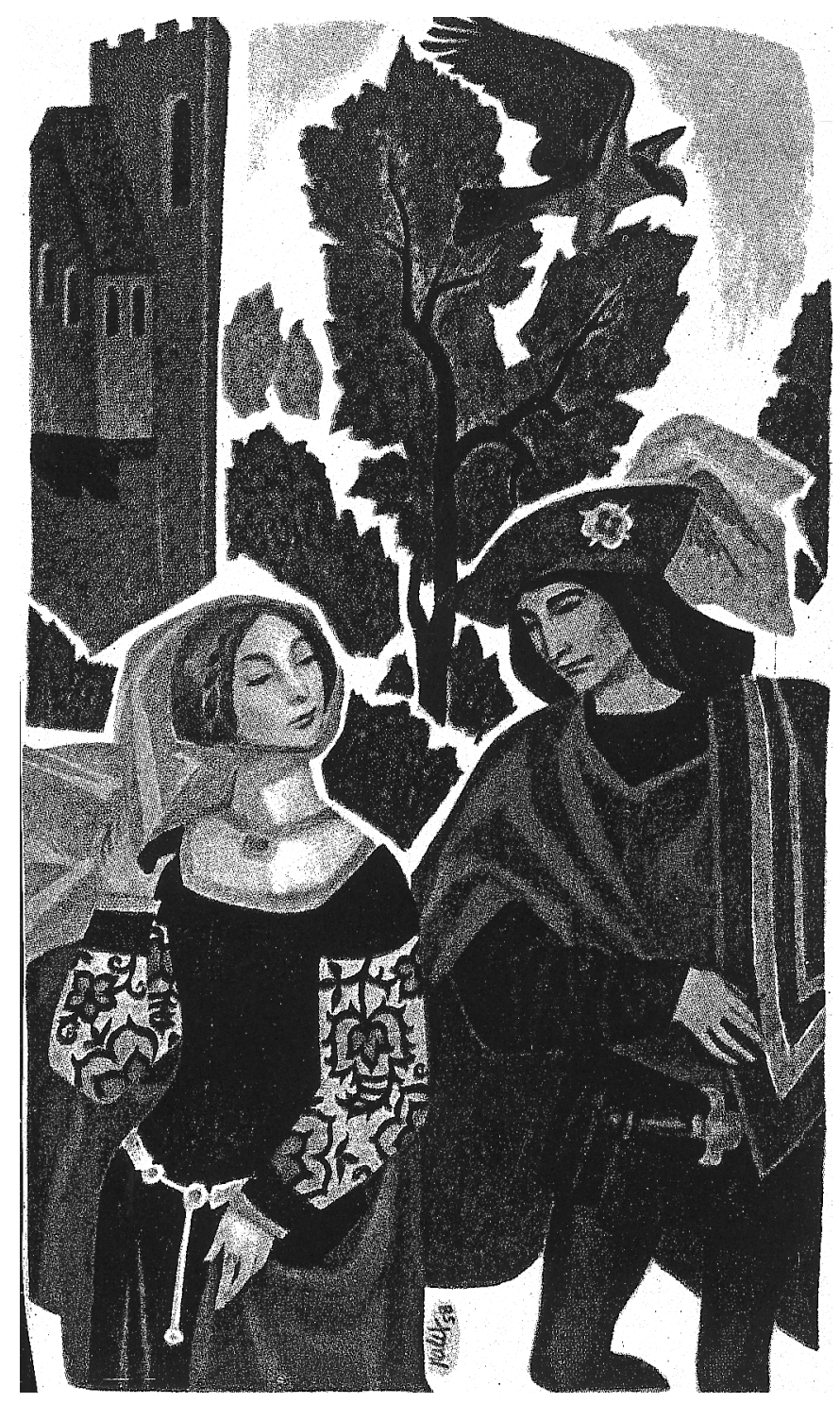

Ilustración de J. Palet, Celestina, Auto I (1959) 